\title{
La favela como espacio de exclusión social en la ciudad de Rio de Janeiro
}

Luz Santa María Muxica. Licenciada en Letras Hispánicas Pontificia Universidad Católica de Chile.

RESUMEN | La favela es parte del imaginario urbano de Rio de Janeiro en la actualidad, pero no siempre ha caracterizado a esta ciudad. Es producto de una serie de transformaciones que esta sufrió a lo largo del siglo pasado y que incluyen aspectos políticos, geográficos, económicos y sociales. Este artículo realiza una breve descripción de esas transformaciones, luego de presentar la ciudad en su geografía, en su historia y en sus símbolos, para así desarrollar someramente un análisis espacial de las novelas brasileñas Ciudad de Dios e Infierno, junto con esbozar el rol que sus autores cumplen en la lógica exclusiva de la sociedad. La exclusión, principal consecuencia -y a la vez causa- de la favela, es tratada desde el punto de vista sistémico, en cuanto parte del supuesto de que la sociedad es funcionalmente diferenciada y se autodescribe como sistema.

PAlabras Clave | Desarrollo urbano, marginalidad, barrios cerrados, transformaciones socioterritoriales.

ABSTRACT | Nowadays, the favela makes up part of the urban imagery of Rio de Janeiro, but it has not always characterized the city. It is the product of a whole set of transformations the city experienced during the last century, and which includepolitical, geographic, economic, and social aspects. After presenting the geography, history and symbolism inherent in this city, the article briefly describes these transformations. The main objective is to develop an initial analysis of the setting for the Brazilian novels Ciudad de Dios and Infierno. Finally, the article attempts to sketch the role that the authors play in the logic of social exclusion. Exclusion, the main consequence -and simultaneously the main cause- of the favela, is addressed from the systems theory point of view, since it conceives society as a system that describes itself by its functionally differentiated character.

KEY WORDS | Urban development, marginality, gated communities, socioterritorial transformations.

Este artículo es parte del seminario para obtener el grado de Licenciatura en Letras por la Pontificia Universidad Católica de Chile, trabajo titulado "La favela de Rio de Janeiro: un espacio de exclusión. Análisis de las novelas Ciudad de Dios, de Paulo Lins, e Infierno, de Patrícia Melo."

Correspondencia: Luz Santa María Muxica.E-mail: 1santama@uc.cl 


\section{Introducción}

En el imaginario colectivo, la favela es un espacio propiamente urbano y que posee significados propios, ya establecidos a nivel global. Difícilmente se la puede asociar a otro país que no sea Brasil, lo que la convierte en un espacio único y de una semiótica inamovible. ¿Qué tan ciertos son esos significados, que ya se han convertido en mitos? Si bien nuestro interés no está en analizar los estereotipos que se han adueñado de la favela y la pobreza desde el exterior, como punto de partida para el presente artículo se hará frente a la favela como un espacio de significados móviles y transpuestos.

En este sentido, la intención radica en analizar y comprender los movimientos y contrastes de la ciudad carioca a la luz de sus características geográficas e históricas, que con la ayuda de los estudios de semiótica que han realizado importantes autores en base a otras ciudades podemos interpretar y así generar nuevas significaciones de esta metrópolis latinoamericana y sus procesos sociales, los que funcionan bajo el mecanismo de la inclusión y la exclusión.

Para esto servirá de apoyo y ejemplificación la consideración de algunos aspectos espaciales de las novelas Ciudad de Dios, de Paulo Lins, e Infierno, de Patrícia Melo. De esta manera será posible identificar y comparar la forma en que estos dos escritores representan la favela carioca, como también la responsabilidad que toma cada uno de ellos hacia este emplazamiento social a partir de sus obras literarias.

\section{Hacia una semiótica de Rio de Janeiro}

$22^{\circ} 54^{\prime} 24^{\prime \prime}$ Sur, 4310'21” Oeste. Estas son las coordenadas geográficas de la ciudad de Rio de Janeiro, ubicada en el sudeste de Brasil, en el litoral atlántico. Su nombre, como explica Teresa Meade, hace referencia a la desembocadura que los portugueses vieron al llegar a esta zona por el mar un mes de enero, por lo que la bautizaron río de enero. Más tarde, los conquistadores se dieron cuenta de que aquello no era la desembocadura de un río, sino la gran bahía de Guanabara, con lo que Rio se convierte en uno de los mayores puertos de Brasil. Emplazada junto al océano Atlántico, el territorio de la ciudad tiene la forma de un rectángulo, en cuanto está cercado por todos sus lados. Por el norte, la bahía limita su extensión, así como lo hace el mar por el poniente. Por sus lados oriente y sur se levantan varias cadenas montañosas, las cuales separan la ciudad del resto del país. Como si esto fuera poco, este rectángulo no tiene una superficie plana, sino escarpada, accidentada por múltiples morros, los que hacen de la ciudad un territorio bastante complejo.

En términos de Lotman, por sus características geográficas y culturales, Rio de Janeiro es un ejemplo de ciudad excéntrica. Es una ciudad que por situarse a orillas del mar y junto a la desembocadura de un río, como creyeron los portugueses, se ubica en un extremo del espacio cultural y, tal como el semiólogo señala en relación a San Petersburgo, por esto mismo es una ciudad que se inclina al despliegue, a la apertura y a los contactos culturales. Haciendo una revisión al texto de Lotman, allí se plantea que las ciudades excéntricas se encuentran en lucha con la naturale- 
za, en cuanto en ellas se privilegia a la razón, pervirtiéndose los órdenes naturales. Rio, por ser una ciudad de accidentada geografía, no posee un territorio de óptimas cualidades para la urbanización. Aún así, los portugueses eligieron esta zona por sobre otras para construir una ciudad-puerto, de la misma manera en que Pedro el Grande luchó hasta construir un suelo de piedras sobre el pantano para poder emplazar su ciudad, como indica la mitología. Por otra parte, el mito de destrucción que circunda la ciudad excéntrica se actualiza en Rio de Janeiro - si bien no es un ejemplo equivalente al de San Petersburgo- mediante la destrucción del morro do São Bento en 1904 para trazar la avenida Rio Branco o Central, que conecta la zona sur con el centro de la ciudad; o la destrucción del morro do Castello en 1921. Así, el símbolo de la traslación antinatural que tiene lugar en Rio se debe al intento de uniformar el suelo de la ciudad, tal como se preparan los suelos para los cultivos en la agricultura. Los morros se han convertido en obstáculos visuales para la conformación del panóptico urbano, manteniéndose así los barrios aislados del centro y tornándose inoperante la circulación concéntrica de la ciudad.

Otra característica de la ciudad excéntrica es su poliglotismo semiótico, como señala Lotman. Esto es, la significación híbrida que la ciudad va constantemente desarrollando al unir códigos y textos diferentes. Para el teórico, esto se da tanto en el plano sincrónico como en el diacrónico. En Rio de Janeiro, este hibridismo, si puede llamársele de esa manera, se manifiesta de diversas formas. Tal como indica Meade (1997), Rio fue desde sus inicios la ciudad más importante de Brasil, en cuanto era el puerto principal por el que entraban y salían todos los productos que conformaban la actividad comercial del país. Además, allí estaba asentada la mayoría de las emergentes industrias, especialmente textiles. Por otro lado, durante el siglo XIX Brasil alcanza un alto nivel en la economía global, sobre todo gracias a la comercialización del café, del cual las ciudades de Rio de Janeiro y São Paulo eran las principales beneficiadas. Esto hacía de Rio una ciudad cosmopolita, vinculada profundamente a la cultura europea a través del intercambio importación/exportación, el cual era manejado por la creciente burguesía urbana. No obstante, no se puede olvidar que hasta finales de este siglo Brasil estaba dominada por el imperio portugués, y así también su economía. Hacia el fin de este gobierno, son los ingleses quienes heredan el liderazgo económico de Brasil, convirtiendo cada vez más a este país en un centro comercial occidental. "La ciudad es un mecanismo que recrea una y otra vez su pasado" (Lotman, 1984, p. 4). A partir de este enunciado, los cambios culturales que las distintas influencias europeas han ejercido sobre Rio se pueden interpretar como un mecanismo mediante el cual se vuelve constantemente sobre el pasado, para desde ahí proyectar el futuro de una nueva manera, bajo diferentes principios. Meade indica que durante el siglo XIX la sociedad de Rio estuvo fuertemente influenciada por la cultura francesa, así como ocurrió en casi toda Latinoamérica, como una manera de hacer tabula rasa con el patrimonio portugués. Así, Francia era el modelo en lo concerniente a la cultura y la moda, mientras Inglaterra era el modelo económico. Por último, otro elemento que da cuenta del hibridismo de la ciudad de Rio es su población. Demográficamente, cuenta con dos núcleos 
principales: portugueses y afroamericanos, los segundos llegados a Brasil en calidad de esclavos de los primeros. Además, Rio es habitado por un grupo considerable de etnias indígenas, algunas de ellas provenientes de noreste del país, como también por una vasta comunidad de judíos, los cuales migraron desde Europa a partir del siglo XVII en adelante, haciendo de Brasil un refugio tan importante como los Países Bajos (Zaluar, 2004).

Muchos otros rasgos podrían destacarse de la ciudad excéntrica, pero sólo uno será relevado en este momento para dar paso al proceso de formación de la favela. Lotman habla de la teatralidad de Petersburgo, la cual genera una clara división entre el espacio escénico y el espacio entre bastidores, y deduce la existencia de un espectador. A partir de esta idea, es interesante identificar la imagen de ciudadpostal que Rio ha creado para sí, en cuanto reconoce la existencia de un espectador encarnado en Europa -y posteriormente en Estados Unidos. Esta ciudad empezó a vivir de y para su decorado, en cuya actuación la burguesía cumplió un rol prominente. Entre bastidores estaba todo el resto de la población, que crecía sin parar y en un espacio no apto para la expansión. Lentamente, el espacio entre bastidores comenzó a ser visible para el espectador y a formar parte del espacio escénico. Entonces la ciudad-postal cambió, y ese espacio otro de los pobres tuvo que ser necesariamente fotografiado como parte del decorado de la ciudad. De esta forma, la favela se transforma en la actualidad en la nueva imagen postal de Rio de Janeiro, mitificándose así justamente lo que había destruido su mito de ciudad occidentalizada y moderna.

El rápido y masivo crecimiento de las favelas en Rio tendría como causa una ola de inmigración rural desde los estados vecinos y del noreste alrededor de 1930, producida por una brusca baja de los precios mundiales de los productos agrícolas brasileños. En la ciudad, el establecimiento de nuevas fábricas y su demanda de mano de obra alteró las modalidades de vida, subiendo también su costo. Cabe señalar que las posibilidades de ampliación de la ciudad eran escasas, por las franjas montañosas que la circundaban y porque los terrenos costeros estaban destinados a convertirse en barrios residenciales de lujo. La solución al problema de las viviendas la brindaron entonces los morros aislados que había dentro de la ciudad y las planicies a su alrededor, donde se emplazaron rápidamente las favelas. Las viviendas eran muy precarias, lo que introducía el elemento rural propio de sus habitantes, contrastando nítidamente con el resto de la ciudad. Resulta interesante enfatizar el hecho de que esta pobreza es geográficamente vertical, no horizontal, como sucede en casi todas las ciudades latinoamericanas. En este contexto, la pobreza como postal adquiere mayor sentido y se podría leer hasta como una batalla no intencional entre la tradición y la modernidad, o entre el campo y la ciudad, la cual cada día se acercaba más a una metrópolis. Esto, bajo el supuesto de que las ciudades serían las encargadas de sacar a su país del subdesarrollo, en cuyo mayor crecimiento se garantizaría el desarrollo nacional y una mejor situación económica para sus habitantes; esto es puesto en jaque en la actualidad por el permanente incremento de la pobreza urbana (Schütz, 1996, p. 48). 
Durante el período del régimen militar de Castello Branco se da comienzo en Rio de Janeiro a grandes proyectos de erradicación de favelas, en pos de mantener un orden social basado en la segregación que asegurara la máxima seguridad y acelerara el proceso del desarrollo económico. Los favelados fueron desalojados de sus casas y trasladados a la periferia a vivir en precarias soluciones habitacionales. Ciudad de Dios fue uno de los mayores proyectos habitacionales que se inicia en este tiempo y se consolida hacia 1976.

Sin embargo, el proceso de erradicación se paraliza, y la principal razón fue el desfinanciamiento estatal a causa de la carencia de recursos de los pobres para pagar sus nuevas casas. Estas quedaban muy lejos de sus trabajos, por lo que tenían que pagar más por locomoción, además de que ahora no contaban con el tiempo para trabajar horas extras. Las mujeres ahora vivían demasiado lejos de las casas lujosas a las que daban servicios, por lo que también carecen de recursos. Así, lo que empieza a suceder es que algunas familias se trasladan a nuevas favelas, ya que estas presentaban las mejores condiciones de vida, vendiéndoles su propiedad en el conjunto a familias de clase media, que sí pueden pagarla. De esta manera se descontrola el sistema y, aunque no en su totalidad, este vuelve a su forma original. La ciudad postal de Rio de Janeiro sigue siendo la favela.

\section{La favela y su funcionamiento como mecanismo de exclusión social}

Resulta interesante ver de qué manera estas políticas de erradicación pueden influir en la posterior conducta de los sujetos marginados.

The systematic use of coercion leaves the lower classes defenceless and inarticulate and, hence, allows the perpetration of endless abuses. This is the heart of the vicious circle in which housing and other welfare programs sponsored by this political system become entangled: they are originally established to alter the image of a regime based on force; in turn, widespread use of force makes possible the perversion of their original goals for the benefit of intervening bureaucracies and their new chosen clienteles. The obligatory silence of the poor, the disarticulation of their organization, permits the existence of these 'welfare' programs and their justification in terms of endless social-justice rhetoric. (Portes, 1979, p. 22).

De este modo, como señala también Janice Perlman (1976), la marginalidad se transforma en una cuestión política no porque algunos estén fuera del sistema, sino porque los sectores de poder se aprovechan de la falta de organización de un sector social para alcanzar sus objetivos, ofreciendo a cambio una relación paternalista. Es en este sentido que las clases populares, los favelados en este caso, ayudan a perpetuar el sistema y a reproducirlo, y no lo revertirán mientras no cuenten con el patrocinio de la misma clase que los reprime, el cual no obtendrán por la imagen desviada que la sociedad tiene de ellos. "The favela helps maintain the status quo by immobilizing the less conservative factors and turning more dynamic the conservative ones" (1976, p. 259). 
Niklas Luhmann, sociólogo alemán del siglo XX, en el marco de una sociedad funcionalmente diferenciada, comprende la necesidad de describir la sociedad tal como es, despojándola de la visión integradora y unificadora con que era estudiada anteriormente y en la que existía mayor preocupación por hacer calzar la sociedad a un esquema que la definiera por completo. En este sentido, él aboga por la autodescripción de la sociedad como sistema. Además, las nociones de individualidad y clase social son cada vez más difusas y, por lo tanto, cada vez menos certeras a la hora de describir la sociedad.

Debido a que este sociólogo pone a la comunicación como la unidad básica de la emergencia de lo social, la inclusión es definida como el modo de tener por relevantes a los seres humanos en el contexto comunicativo, es decir, en la medida en que son tratados como personas o actores sociales, participantes del acto comunicativo. La exclusión, por supuesto, es lo contrario. Son las condiciones no indicadas para pertenecer a un sistema y, a la vez, es el efecto secundario en la operación autodescriptiva de la sociedad, por lo que se requiere esfuerzo para hacerse cargo de ella. Aun cuando esta distinción se plantee en el plano comunicativo, la inclusión y la exclusión deben ser vistas dentro de límites espaciales en virtud de controlar el movimiento de los cuerpos, siendo rasgo fundamental entonces la espacialidad de la exclusión ${ }^{1}$.

En la sociedad funcionalmente diferenciada, cada sistema actúa con independencia de los demás, por lo que las desigualdades o los condicionamientos del uso de la libertad están justificados por cada sistema por separado. De esta manera, la regulación de la inclusión y la exclusión es confiada por entero a los sistemas funcionales. Por el contrario, en las sociedades premodernas, ser excluido de un sistema era amortiguado por el hecho de que este traslado acarreaba la inclusión en algún otro. Ahora, la sociedad no puede hacerse cargo de la pertenencia de los individuos a los sistemas, porque la autopoiésis ${ }^{2}$ de cada uno es demasiado fuerte y porque además opera en autorreferencialidad ${ }^{3}$. Está abierto a la incorporación de energía y prestaciones del entorno, pero cerrado en sus operaciones.

Las teorías clásicas de modernización, señala Luhmann, postulan que si todos los sistemas de una sociedad se plantearan como meta el acceso a fenómenos como la economía de mercado, la democracia, el Estado de Derecho o la alfabetización, se llegaría rápidamente a la modernización. Sin embargo, es cosa de mirar hacia afuera para comprobar que en muchas regiones esto no ocurre tan fácilmente, debido a que el tránsito de la premodernidad a la diferenciación funcional es demasiado brusco y no internalizado por la sociedad. En los países en vías a la modernización -si es que puede hablarse de una modernización total y universalista- hay, por el contrario, un gran abismo entre la inclusión y exclusión, siendo un grupo el recipiente de los beneficios y generador de nuevas riquezas, mientras otro está totalmente privado de

1 Luhmann señala cuatro grandes ámbitos en los que opera la exclusión en las sociedades actuales. Estos son la espacialidad, la corporeidad, el parasitismo y la integración. Para este artículo solo fue desarrollada la espacialidad.

2 Capacidad de un sistema de producirse a sí mismo mediante la reproducción de sus elementos.

3 Propiedad de los sistemas de entablar relaciones consigo mismos y diferenciarse del entorno. 
las prestaciones del sistema funcional. Este es el llamado "obstáculo al desarrollo", en el cual los grupos incluidos cumplen el rol de mantener esta diferencia, y esto es justamente lo que vemos que ocurre en Rio de Janeiro.

A modo de síntesis y estableciendo relaciones con los estudios que se han hecho sobre las favelas específicamente, es necesario referirse al trabajo de Janice Perlman, quien ofrece varios puntos a considerar. Perlman hace una presentación de la teoría de la marginalidad, que es justamente a lo que tanto ella como Luhmann se oponen, para establecer los mitos que esta genera y que además funciona como mantención del statu quo ante la desigualdad social. A grandes rasgos, la teoría de la marginalización se refiere a las conductas que serían intrínsecas en los sujetos marginales y que serían la causa de su exclusión, como si esta tuviera lugar por la carencia de los patrones de conducta que rigen a toda la sociedad. En otras palabras, se considera marginalidad como desviación de personalidad, como falta de adaptación social. Esto genera el círculo vicioso de la pobreza, de la locura, de la criminalidad y de toda desviación a la norma, ya que la solución que se les da a estos sujetos es netamente paternalista y, en último término, de ayuda caritativa. De alguna manera se considera que los marginados viven en esta condición por naturaleza, jamás se asume la marginalidad como un hecho provocado. A partir de esta noción de marginalidad, que es la que prevaleció hasta hace poco tiempo entre los cientistas sociales, Perlman señala en relación a las favelas:

The evidence strongly indicates that the favelados are not marginal but, in fact, integrated into the society, although in damage to their own interests. They are certainly not separated from, or on the margins of the system, but are tightly bound into it in a severely asymmetrical form. They compromise their hard work, their high hopes, and their loyalties, but they do not benefit from the goods and services of the system. It is my contention that the favela residents are not economically and politically marginal, but are exploited and repressed; that they are not socially and culturally marginal, but are stigmatized and excluded from a closed social system. Rather than being passively marginal in terms of their own attitudes and behaviour, they are being actively marginalized by the system and by public policy (Perlman, 1976, p. 195).

De esta forma, se puede inferir que, aun estando fuera del sistema, los excluidos son de extrema funcionalidad para el mismo sistema. Este se sirve de ellos en el entorno para reducir complejidad, lo propio de todo sistema funcional, y así perpetuar la diferencia, que es obligatoria para que exista la inclusión.

\section{Contextualización de las novelas}

Luiz Eduardo do Amaral (2003) hace un trabajo centrado en la literatura brasileña que ha tomado como espacio la favela. Lo que hace es agrupar esta narrativa en dos categorías basadas en la representación que las novelas hacen de la favela: favela infierno y favela idilio. En relación a Lins, do Amaral afirma que el marco inaugural de la literatura de favela como género se da con el lanzamiento de Ciudad de Dios. La relevancia de esta novela frente a la narrativa anterior centrada en estos espacios 
estaría dada por el hecho de ser Lins un ex morador de la favela que él describe. Pero, además, por la capacidad de adueñarse del espacio y construir una historia autónoma, porque es capaz de erigir la historia en una favela inserta en la economía neoliberal, una favela de la postmodernidad. También habla de la cualidad etnográfica de la obra, en cuanto ésta es fruto de una serie de estudios antropológicos a cargo de Alba Zaluar (2004), lo que haría a la novela un testimonio mediado y novela pseudotestimonial o, como señala Ribeiro (2003), una narrativa de "automodelagem artística". En cuanto a la tipología de favela, do Amaral señala que Lins elige una línea intermedia entre el infierno y el idilio, ya que el narrador enuncia tanto lo negativo como lo positivo, destruyendo el maniqueísmo simplista y tentador de tender hacia un solo polo (2003, p. 75). Por eso, en la novela no hay buenos ni malos a priori, cada cual puede ser las dos cosas al mismo tiempo y pasar de la una a la otra indistintamente.

Paulo Jorge Ribeiro se detiene en la importancia de esta obra como transgresora del orden establecido de representación, en cuanto los personajes protagonistas -niños y jóvenes negros involucrados en el narcotráfico o, en palabras de Ribeiro, los “otros fantasmagóricos" - son aquellos que eran considerados sólo por estudios académicos, no por el canon artístico y literario. De esta manera, Ciudad de Dios se plantea como una crítica a la representación vertical de la sociedad:

Contudo, é possível perceber que o testemunho invocado por Cidade de Deus empreende à suspensão das vozes verticalizadas de representação estética e política que foram uma constante nos padrões nacionais deste sistema de representação. De toda forma, a presença de Cidade de Deus nesta arena apresentou um novo posicionamento e apresentação da violência, politicamente mais democrática e procurando a horizontalidade, já que indica que qualquer vida assim pode ter um tipo, singular e ao mesmo tempo exemplar, de representatividade (Beverley, 1993, p.75), mesmo que esta representatividade ainda assuma aqui perfis mais antropológicos do que estéticos e mesmo políticos (Ribeiro, 2003, p. 128).

Así, siguiendo a Ribeiro, Lins establecería una "zona de contacto" entre la cultura dominante y la subordinada a partir de su novela, comprobando con esto su eficacia política, estética y cultural.

Por otro lado, Paulo Roberto Tonani señala que Paulo Lins se instala dentro de la favela en su proceso de escritura: "Ao apresentar-se como exmorador da favela por ele romanceada, Paulo Lins passa a ser 'personagem, ator, agente que se situa naquele mesmo espaço físico, arquitectônico e simbólico de exclusão de que fala"” (2006, p. 45). El crimen es el elemento configurador de la historia en cuanto impulso creador de los discursos, y el narrador necesita de este evento para existir. Además, según Tonani el narrador es un ente totalizador, se mueve por los distintos espacios de la favela sin dificultades relatando con pleno detalle todos los eventos de crimen que tienen lugar, de modo que el lenguaje no se contrae nunca frente al horror. Así, la favela no es sólo una ambientación o escenario para los personajes y sus acciones, sino que es donde toman forma las singularidades de estos. Así, se evidencia la idea de que el espacio y el territorio conforman y dan sentido a la trayectoria de los individuos. 
Do Amaral también dedica algunas páginas a Patrícia Melo, enfocándose en su novela Infierno, la cual es parte del trabajo que da origen a este artículo. Si bien esta novela tiene lugar en el espacio de la favela, según este crítico no entraría en un posible género de literatura de favela. En sus palabras, a Infierno le falta dialogar con este espacio. Ocupa el solo lugar de escenario y de ambientación para la historia, lo que radicaría en la falta de conocimiento de la autora sobre las favelas. Ella dice en entrevistas nunca haber entrado a una, salvo una visita a Rocinha cuando ya había escrito casi la mitad de la novela. Por esto, en la obra de Melo faltaría el vínculo entre la enunciación y lo enunciado. Al no ser parte de una tradición literaria de la favela, las categorías de favela infierno e idilio no serían aplicables a Infierno.

Paulo Roberto Tonani sigue la misma línea de crítica que do Amaral, la cual se basa en el extranjerismo de Melo al espacio de la favela. Este crítico señala que "a produçao literária brasileira que versa sobre a violência recorre de forma constante a uma linguagem realista com o intuito de produzir uma obra mimética, uma cópia do real" (2006, p. 69), y es por esto que Melo se alegra al comprobar que la favela -en su visita a Rocinha- es tal como ella la había descrito bajo el nombre de morro do Berimbau, una favela ficcional. Este indica que la forma en que el extranjerismo se deja ver en la novela es, por ejemplo, en la imagen del morro como laberinto, imposible de ser atravesado. Para Tonani, esto refleja la conciencia de la autora de su incapacidad de asir la realidad de la favela, la cual es física y también social. Lo mismo se reflejaría también en la imagen de este espacio desde arriba, desde la cima del morro, como ocurre al comienzo de la novela. Además, así como Lins opta por construir la narración en torno a la criminalidad, Melo optaría por una narración en torno a la marginalidad, lo que le sirve para hacer de la favela un palco desde el cual observar la totalidad de la ciudad. No así Lins, quien convierte la totalidad de la ciudad en Ciudad de Dios.

\section{La espacialidad en las novelas}

Lo que vuelve a Ciudad de Dios e Infierno novelas similares y aptas para ser analizadas en conjunto es que ambas están configuradas en el espacio de la favela; la primera en la existente favela de Ciudad de Dios y la segunda en el ficticio morro do Berimbau. Tal como se señala en las novelas, Ciudad de Dios se emplaza entre Barra de Tijuca, en la zona sur de Rio, y Jacarepaguá, al oriente de la ciudad. El morro do Berimbau estaría situado entre el centro y la zona sur; se dice que está detrás de Copacabana, desde donde la favela se puede ver ${ }^{4}$.

Busca-Pés es el personaje que, al comienzo de Ciudad de Dios, escenifica la favela, describe el espacio y lo inserta en un tiempo determinado. Sobre una narración in extrema res, Busca-Pé recuerda el pasado, y en este alude a la naturaleza que ahora es ocupada por las construcciones. De esta manera, se hace referencia

4 Paulo Roberto Tonani señala que, según las indicaciones de la ubicación del morro do Berimbau en la novela, estaría situado en el mismo lugar donde estuvo emplazada la favela Catacumba, antes de su erradicación y destrucción.

5 Los nombres de los personajes han sido cambiados de los originales en la versión traducida al español, la cual es usada para este trabajo. Por esto, puede que muchos nombres no coincidan. 
al mito de fundación de la ciudad que explica Lotman: Rio de Janeiro sufre constantes transformaciones, en las cuales el artificio vence y le va ganando terreno a la naturaleza.

Reposó la mirada en el lecho del río, que en toda su superficie se abría en circunferencias a las gotas de llovizna, y sus iris, en un zoom de color castaño, le trajeron a la mente imágenes evocadoras del pasado: el río limpio; el guayabal que, una vez cortado, había dado paso a los nuevos bloques de pisos; algunas plazas, ahora ocupadas por casas; los ciruelos de Java asesinados, así como la higuera embrujada y los papayos; el caserón abandonado que tenía piscina y los campos de Paúra y Baluarte, donde había jugado a la pelota defendiendo el diente de leche de Oberom; todos ellos habían desaparecido para dar lugar a las fábricas (Lins, 1997, pp. 15-16).

Así, se introduce también el río como elemento configurador del espacio de la favela. En un afán contextualizador, el narrador señala que el río divide dos partes de la ciudad: la de los portugueses y la de los esclavos. En "el lado de acá" es donde se encontraban las huertas de Portugal Pequeno, trabajadas por los esclavos desde hacía años, así como también los caserones, embrujados de tan viejos que eran, lugar en el que un día las máquinas arrasaron con los árboles y terraplenaron el pantano, para dar paso al desierto en que se construiría un nuevo barrio. Ahora el pantano está organizado por zonas de nombres deícticos, lo cual exacerba la descripción espacial de Ciudad de Dios en la novela. Estas zonas son: "Allá Arriba”, "Allá Enfrente”, "Allá Abajo", "Otro Lado del Río" y "Los Apês" - aunque más adelante se nombran la quadra 13 y 15 también. Los brazos del río cortan este pantano: el derecho pasa por en medio y el izquierdo separa Los Apês del resto de la favela, aunque está unida por el principal puente de Ciudad de Dios. El Otro Lado del Río, junto al bosque, mantiene su verdor, y por estar separado mantendrá siempre cierta independencia frente al resto del barrio. Allí también se encuentran las casas más pequeñas y viven los principales panaderos y lecheros del barrio. En Allá Arriba y Allá Enfrente se vende marihuana y se encuentra el "cafetín el Bonfím" y el "bar de Batman" respectivamente, aunque luego también en Los Apês se crea un puesto de venta de droga. Allá Arriba y Los Apês son los espacios más importantes a lo largo de la novela, ya que en ellos viven los líderes de las pandillas más grandes de la favela y por esto se desarrolla una enorme competencia que va a terminar en una guerra hacia el último episodio de la novela. En este momento de la narración, Zé Miudo es el dueño de Los Apês por medio del mando del narcotráfico de esta zona, según el cual es la mejor ubicada por estar más cerca de la zona sur, oeste, norte y los suburbios de la zona central de la ciudad. Zé Miudo, el más temible de todos los maleantes que han vivido en Ciudad de Dios, es quien no quiere permitir que este sea un barrio, como lo han intentado sus habitantes; desea que se mantenga como favela y que no pierda la barbaridad y salvajismo que es propio de este espacio. De ahí la necesidad de no descuidar la violencia y la criminalidad. Él era el rey de la calle, y como tal, debía imponer su poder diariamente.

Se dice que muchas familias comenzaron a mudarse a Ciudad de Dios desde las favelas y de la Baixada Fluminense luego de las crecidas que dejaron a los habitantes de las favelas de Rio sin viviendas. Si bien los autores consultados señalan que la 
causa de este movimiento fueron los programas de erradicación de las favelas entre los años 60 y 70, Rio de Janeiro es una región que ha sufrido constantes inundaciones y derrumbes a lo largo de su historia, de modo que al optar Paulo Lins por esta razón hace patente su intento por aportar al mito de la ciudad como continua destrucción y reconstrucción, como ciudad en que luchan la naturaleza y la modernización. La entrada a Ciudad de Dios desde el estadio Mario Filho -lugar en que las víctimas estaban refugiadas- era visto como una bendición por las familias, todos cantaban: "Ciudad maravillosa, llena de encantos mil..." (Lins, 1997, p. 21). Los niños gozaban con el paisaje campestre, aunque esta misma lejanía del centro de la ciudad hacía a los adultos reconsiderar el traslado. Pero la oportunidad de adquirir una casa propia era siempre más fuerte y por esto cientos de familias llegaban cada día a establecerse al nuevo barrio. Así es como Ciudad de Dios se vuelve la reina de todas las favelas, se vuelve la esperanza de cada cual de habitar un lugar tranquilo y sin delincuencia; se vuelve el mito por el cual la criminalidad es destruida y un nuevo espacio de paz es restituido en su lugar. Sin embargo, pese a las esperanzas, esto no ocurre. Los grandes delincuentes de las favelas llegan a Ciudad de Dios a competir por los espacios y por el poder, ya que quieren ser igual de importantes a como lo eran antes. La favela se vuelve cada vez más violenta, de modo que para conseguir un trabajo se torna primordial la pregunta “¿Dónde vives?” Si se era de Ciudad de Dios no había ningún trabajo disponible.

Cabe destacar que la riqueza espacial de la novela sumada a la gran cantidad de personajes de igual profundidad narrativa da cuenta de la opción del autor por hacerse cargo de una literatura de la favela, configurando su universo en totalidad, más allá de los personajes que puedan habitarla. Sí es importante el acontecer, pero no tanto quiénes lo llevan a cabo. De esta forma, se identifica en Ciudad de Dios un carácter más documentalista que narrativo, sin ser por esto de menor calidad la técnica escritural del autor. Siguiendo la categorización que ocupa do Amaral, el profundo diálogo con el espacio de la favela en la novela aporta a la consideración de esta como novela pseudotestimonial, en la cual se privilegia una mediación a nivel de narrador, no de personajes. Para graficar esta idea ayuda lo planteado por Tonani: "Nesse ambiente de fragilidade retratado no romance de Lins, a violência e o narrador podem ser vistos como as únicas estruturas sólidas” (2006, p. 54). Tal como se dijo anteriormente, la violencia aparece en la novela como el impulso generador de los discursos y como el elemento obligado para la existencia del narrador. Esta solidez, por tanto, fomenta la no realización de los personajes y, a la vez, la representación de la favela como un espacio debilitado por la exclusión social.

Al mismo tiempo, el narrador omnisciente de Ciudad de Dios es también un narrador testigo, en su más literal sentido, ya que es un testigo observador de la realidad. Es un caminante que por su omnisciencia conoce la ciudad completamente y va narrando los acontecimientos de criminalidad por medio de su observación. De este modo, se instala en los cimientos de la novela el sentido de la vista, pero el cual opera hacia dentro de la ciudad, no hacia fuera. Ciudad de Dios se mira a sí misma a través de un observador oriundo, no existe en ella la mirada externa y por esto es 
que el observador nunca se esconde frente al horror. En este sentido es que la favela pasa a ser la ciudad. Por esto, si volvemos a la conceptualización de la favela como imagen postal de Rio, vemos que en Ciudad de Dios esta se rompe. No hay visualización panorámica o desde arriba; al contrario que en Infierno, el espacio planteado por Lins no es mimético ni fotografiable, sino que pura vivencia y un entramado tan complejo como el sistema social que representa.

Más adelante en la narración, Busca-Pé es nuevamente el personaje que se hace cargo de las transformaciones de la favela. Él llora por la manipulación que hacen los tractores de la tierra virgen en la que había jugado durante su infancia. De esta manera, Busca-Pé se plantea como el personaje que establece el nexo con el pasado, pero con el pasado colonial: él y Barbantinho, en una alucinación, ven a los esclavos negros siendo torturados por el barón de un caserón en ruinas que en el pasado estuvo situado ahí. Por otro lado, Busca-Pé es el único personaje que no presenta los rasgos de la exclusión, sino que logra insertarse oblicuamente en el sistema, por lo que se puede inferir que su vínculo con el pasado es también el vínculo con la inclusión.

El personaje que introduce la espacialidad en Infierno es Reizinho, José Luís Reis, el protagonista de la novela. Siendo sólo un niño de once años, él comienza su trabajo para el narcotráfico como ojeador, es decir, vigilante de los accesos del morro para que no entre la policía. Desde ahí "se ven muchas parabólicas y tejados acanalados. Aviones volando bajo. Basura. Perros defecando entre la maleza. Trenes. Edificios de dos plantas. Cabinas de teléfono, colas” (Melo, 2000, p. 12), por lo que ya en la segunda página de la novela se tiene una idea de cómo es esta favela, o al menos desde los ojos de qué personaje lo es. Luego se enuncia que Reizinho sólo ve a las personas, no los trayectos, calles y carteles. De esta forma, el protagonista lee de su entorno las acciones de las personas, las relaciones, mas no el escenario, instalándose así una primera opción por parte del autor: privilegiar el acontecer por sobre el contexto espacio-temporal, al contrario de lo que ocurriría en Ciudad de Dios. En la novela de Patrícia Melo sí se encuentra una jerarquía en los personajes y, si bien estos son bastantes, hay una preocupación por parte del escritor por construirlos de manera acabada. Así, no hay miedo de crear una ficción, y esto permite que la narratividad sea superior al documentalismo. A Reizinho le gusta observar, señala el narrador, pero no desde arriba, abarcando todo el conjunto; le gustan los detalles y esto refuerza la idea de subjetivismo de la obra. Es Miltão, el líder del narcotráfico del Berimbau, quien cuando empieza la guerra contra el morro dos Marrecos sube a la cima y se instala ahí para observarlo todo, para no perder el control de su favela. De esta manera, si en Ciudad de Dios el narrador era un caminante, el narrador de Infierno sobrevuela el espacio, no estableciendo el diálogo con la favela. No conoce la totalidad de sus calles, por lo que para este constituyen un laberinto. Así, el narrador intenta seguirle la pista desde arriba a Reizinho, quien está empezando a conocer la favela y todo lo que en ella se esconde: narcotráfico, tradiciones, identidad, sueños, etc. Aquí la observación es menos acuciosa, se reserva solo para Reizinho, quien, por su parte, privilegiará otro sentido que en Ciudad de Dios: el olfato. 
Como ya se dijo, Reizinho es un personaje observador, pero que se fija en los detalles, que mira desde cerca, no desde arriba. Además, le gustan los detalles que la gente esconde, como la fealdad y lo grotesco, lo que avergüenza a cada uno. Por el narrador también se sabe que a Reizinho le gusta observar a los perros al caminar, animal que acompaña al protagonista durante toda la novela, y no uno solo, sino que en jauría. Así, se podría decir que la presencia de los perros alrededor del personaje, sumado al carácter de descriptor del mismo, haría relevante el sentido del olfato, en cuanto este permite percibir lo que no es observable, tocable, ni oíble. Por medio de este sentido se puede acceder a lo oculto, tanto a lo que está vedado en las demás personas como en el espacio. De esta manera, el hecho de que el narrador sea guiado por Reizinho a través de su sentido del olfato y el de los perros que lo acompañan es revelador de la opción de la autora, quien se haría cargo de su falta de conocimiento de la realidad narrada mediante esta estrategia, en el sentido de que sólo un personaje de la misma favela puede ser el vocero de su espacio, que está oculto para el resto de la ciudad. Al mismo tiempo, Reizinho en un momento se compra una cámara de video, con la cual filma el día a día de la favela, sus colores, sus habitantes y sus perros, entre otras cosas. Por esto, este personaje se puede vincular a Busca-Pé, de Ciudad de Dios, quienes mediante sus aficiones a la fotografía realizan una función descriptora del espacio y ayuda para el narrador.

Por otro lado, Patrícia Melo retoma la imagen de la favela como la nueva fotografía postal de Rio de Janeiro por medio de un personaje de Estados Unidos que visita el morro para grabar un comercial en él. Aquí se plantea la favela como un escenario pintoresco, exótico y colorido, y como un espacio que abarca todo el resto de Brasil. “(...) es la favela en sí, es el color, el movimiento, me encantan las favelas. Eso es Río. Eso es Brasil. Las favelas, para mí, son la esencia de este país. Así es Brasil. No quiero nada demasiado bonito, quiero decir, pintado de azul. Quiero la propia realidad, con toda su fuerza" (Melo, 2000, p. 292) ${ }^{6}$. Por medio de este pasaje se puede ver que la imagen postal de la favela es la esencia de la opción de la autora y que la misma trayectoria de la narración se origina en la fotografía desde las alturas. Aquí, la favela es mímesis; es imitación de una realidad compleja, pero jamás cognoscible desde su interior, sino solo desde su totalidad panorámica.

La referencia al centro de la ciudad que se realiza en la novela es sólo asociada a los pordioseros y vagabundos, al igual que en la novela Ciudad de Dios. Estos ensucian la ciudad con su falta de pertenencia a un lugar, convirtiéndose en los echados o los sinlugar. Pareciera que ambas novelas configuran sus propios espacios de significación en un centro que es la favela, y no cualquiera, sino una sola favela. El centro de la ciudad pierde así su semiótica de centro v/s periferia y pasa a ser un espacio de mera referencia geográfica y de hogar para los indigentes, mientras el verdadero emplazamiento de oposición a la favela es la zona sur, la zona residencial de clase alta de Rio.

6 El filme Orfeo negro, 1959, dirigido por Marcel Camus y escrito por él mismo y Vinicius de Moraes, es la traducción brasileña de la tragedia de Orfeo y Eurídice, en la que se reproduce esta misma imagen de Rio de Janeiro y Brasil, pero en la ficticia favela Babilonia -cuyo nombre también aporta míticamente a la representación si se sigue a Toporov. Se muestran los elementos más característicos de la ciudad, como el carnaval, los múltiples colores, la samba, el bossa nova y los morros. Se muestra también una pobreza feliz y protagonista de la ciudad, lo cual se ve reforzado por el tiempo del carnaval en el que acontece la historia. 


\section{Conclusión}

Como se vio en este breve análisis, ninguno de los dos escritores tiene la intención de describir categórica ni simplistamente la favela, sino, por el contrario, hacer de sus habitantes los protagonistas de una historia, dándoles la oportunidad de ser parte del sistema desde la literatura. Lins se inserta cabalmente en el género de la naciente literatura de favela, mientras Melo se acerca a este espacio desde el género neopolicial, aunque no lo trabaje en esta ocasión. De esta forma, ambos realizan una labor inclusiva en sus opciones por la favela, la cual no radica en la tematización de las novelas -ya que sin duda aquello terminaría reduciendo esta realidad-, sino que es una inclusión realizada desde el sistema literario. Lins, mediante la construcción de una novela que se demora casi diez años, basado en material etnográfico, con un carácter muy documental pero sin dejar de ser por ello una gran obra literaria, logra que la crítica lo postule como el escritor inaugural del género de literatura de favela. Esto, sumado a la vasta recepción a nivel mundial de la novela y a la filmación de la película que se basa en ésta, permite que Lins pueda ser considerado como un autor canónico o, por lo menos, bordeando el canon. Melo, por su parte, al ser ya reconocida por la crítica debido a sus incursiones en la novela negra, logra que el canon se acerque a la realidad de la favela, convirtiéndose no en una representante de la literatura de favela, sino en una escritora canónica de este espacio. De esta forma, por medio del traslado hacia el canon es que ambos autores realizan la inclusión de los favelados y sus relaciones al sistema.

En este desplazamiento hacia el canon, los autores se sirven de todos los sistemas para configurar sus novelas, tanto del político y del económico, como del cultural y jurídico, intercambiando elementos de estos con la literatura en todo momento, sobre todo porque la exclusión se define justamente en relación a la no pertenencia a ellos. De esta forma, la obra literaria se convierte en un todo isomórfico a la propia cultura, se convierte en una manifestación de iguales condiciones a cualquier hecho social, cuya representación no puede considerarse unívoca ni unidireccional, sino como una correlación de intercambios mutuos, jamás determinante el uno del otro. Esto hace pensar en la idea fenomenológica de la caja negra, negrura que es intrínseca a toda observación, ya sea de un hecho social o cultural, como de las representaciones de esta índole realizadas en una obra literaria. En esta interacción de estructuras literarias y extraliterarias los textos pasan a ser generadores de nuevos sentidos, en cuyas semióticas se actualizan y se proponen nuevos significados, como lo es el de la exclusión, la marginalidad, la ciudad y la violencia, todo esto inserto en el contexto del Rio de Janeiro de los últimos treinta años.

En este sentido, se hace necesario relevar el hecho de que Paulo Lins y Patrícia Melo, así como también lo hacen muchos escritores latinoamericanos, realizan en sus trabajos el rescate de un sector social junto con el de un espacio urbano que quedan fuera de la lógica funcional de la modernidad y que por lo mismo no tienen voz en ella. Aun así, su mérito no radica en una denuncia o en un simple 
gesto caritativo, sino en la reivindicación de una parte considerable de la sociedad mediante su representación como sistema de interacción igualmente complejo que el resto de los sistemas y en la confirmación de la extrema funcionalidad de la favela y sus habitantes para la totalidad de la ciudad. Como tal, la imagen de ciudad-postal de la favela es el símbolo que materializa la lógica de la exclusión de Rio de Janeiro y que representa el obstáculo al desarrollo, en cuanto demuestra la conveniente convivencia entre el sistema y su entorno para el feliz funcionamiento de la urbe. IEURE

\section{Referencias bibliográficas}

Do Amaral, L. E. (2003). Tesis: Vozes da favela representaçöes da favela em Carolina de Jesus, Paulo Lins Luiz Paulo Corrêa e Castro. Rio de Janeiro: PUC.

Even-Zohar, I. (1990). El sistema literario. Trad. Ricardo Bermúdez Otero. Itamar Even-Zohar's site. Recuperado el 18 abril de 2007, de http://www.tau.ac.il/ itamarez/

Greene, R. (2004). Ciudad de Dios: tan lejos de la postal, tan cerca del infierno. Eure, 30, 91, 121-126. Lins, P. (1997). Ciudad de Dios. Trad. Mario Merlino. Barcelona: Tusquets.

Lotman, I. M. (1984). Símbolos de Petersburgo y problemas de semiótica urbana. Trad. Ángel Luis Encinas Moral. Entretextos. Revista electrónica semestral de estudios semióticos de la cultura. Recuperado el 04 marzo de 2007, de http://www.ugr.es/ mcaceres/Entretextos/entre4/ petersburgo.html

Lotman, I. M. (1996). El texto en el texto. En D. Navarro (Ed.). La semiósfera. I. Semiótica de la cultura $y$ del texto. Madrid: Cátedra.

Luhmann, N. (1971). Teoría de la sociedad. México: Universidad Iberoamericana.

Luhmann, N. (1997). La sociedad de la sociedad. Trad. Javier Torres Nafarrate. México: Herder.

Luhmann, N. (1998). Inclusión y exclusión. En J. Beriain \& J. M. García Blanco (Eds.). Complejidady modernidad. De la unidad a la diferencia. Madrid: Editorial Trotta.

Meade, T. A. (1997). "Civilizing" Rio: reform and resistance in a Brazilian city, 1889-1930. University Park, Pa.: Pennsylvania State University Press.

Pearse, A. (1967). Algunas características de la urbanización en Rio de Janeiro. La urbanización en América Latina. En P. M. Hauser (Ed.). Buenos Aires: Unesco y Ediciones Solar.

Melo, P. Infierno. (2000). Trad. Rita da Costa. Barcelona: DeBols!llo.

Perlman, J. E. (1976). The myth of marginality. Urban poverty and politics in Rio de Janeiro. California: University of California Press.

Pino, J. C. (1997). Sources on the history of favelas in Rio de Janeiro. Latin American Research Review, $32,3,111-122$.

Portes, A. (1979). Housing policy, urban poverty, and the state: the favelas of Rio de Janeiro, 1972 1976. Latin American Research Review, 14, 2, 3-24.

Ribeiro, P. J. (2003). Cidade de Deus na zona de contato - alguns impasses da crítica cultural contemporânea. Revista de crítica literaria latinoamericana, XXIX, 57, 125-139.

Schütz, E. J. (1996). Ciudades de América Latina. Desarrollo barrial y vivienda. Santiago de Chile: Ediciones Sur. 
Tonani, P. R. (2006). Tesis: Entre o morro e o asfalto: imagens da favela nos discursos culturais brasileiros. Rio de Janeiro: PUC.

Toporov, V. (1987). El texto de la ciudad-doncella y de la ciudad-ramera desde una perspectiva mitológica. Trad. Klaarika Kaldjärv. Entretextos. Revista electrónica semestral de estudios semióticos de la cultura, 8. Recuperado el 06 de mayo de 2007, de http://www.ugr.es/ mcaceres/entretextos/entre8/toporov.html

Zaluar, Alba. (2004). Violencia, crimen e impunidad. Las paradojas de la democracia en Brasil. Conferencia dictada en la Cátedra UNESCO. Rio de Janeiro: Universidade do Estado do Rio de Janeiro. Recuperado el 07 de mayo de 2007, de http://www.insumisos.com/lecturasinsumisas/Paradojas\%20de\%20la\%20democracia\%20en\%20Brasil.pdf 